\title{
Mineração
}

\section{Caracterização hidrodinâmica de células mecânicas de flotação: capacidade de bombeamento de célula Denver de laboratório}

\author{
Odair Alves de Lima \\ Doutorando em Engenharia Mineral- EPUSP - Departamento de Engenharia de Minas e de Petróleo \\ Escola Politécnica, Universidade de São Paulo, São Paulo, SP, Brasil \\ E-mail:odair.lima@poli.usp.br \\ Laurindo de Salles Leal Filho \\ Professor Titular de Tratamento de Minérios, Departamento de Engenharia de Minas e de Petróleo \\ Escola Politécnica, Universidade de São Paulo, São Paulo, SP, Brasil \\ E-mail: lauleal@usp.br \\ Flávio Spínola Barbosa \\ Centro Tecnológico de Hidráulica - Universidade de São Paulo \\ E-mail:flavio@cth.usp.br
}

\section{Resumo}

A capacidade de bombeamento de rotores pode ser expressa em função de sua vazão de bombeamento $\left(Q_{b}\right)$ ou de seu número de bombeamento $\left(\mathrm{N}_{\mathrm{Q}}\right)$. Ambos parâmetros são muito úteis na caracterização hidrodinâmica de células mecânicas de flotação. Nesse trabalho, utilizouse o micromolinete, para determinar $\mathrm{Q}_{\mathrm{b}}, \mathrm{N}_{\mathrm{Q}}$ e, também, a velocidade de escoamento da água $\left(\mathrm{v}_{\mathrm{b}}\right)$, na descarga do sistema rotor/estator de uma célula Denver, modelo de laboratório. Em sua faixa de trabalho (900rpm $<\mathrm{N}<1400 \mathrm{rpm}$ ), tanto na ausência, como na presença de ar, tal equipamento operou com $\mathrm{v}_{\mathrm{b}}=20-30 \mathrm{~cm} / \mathrm{s}, \mathrm{Q}_{\mathrm{b}}=298-454 \mathrm{~cm}^{3} / \mathrm{s} \mathrm{e}$ $\mathrm{N}_{\mathrm{Q}} \sim 0,06$. $\mathrm{O}$ valor de $\mathrm{N}_{\mathrm{Q}}$ do modelo de laboratório exibiu valor muito próximo ao de uma célula industrial $\left(\mathrm{N}_{\mathrm{Q}} \sim 0,05\right)$. Tal constatação indica que $\mathrm{N}_{\mathrm{Q}}$ pode ser útil no escalonamento de equipamentos. A presença de ar no sistema se mostrou capaz de diminuir a magnitude, tanto de $\mathrm{v}_{\mathrm{b}}$, quanto de $Q_{b}$, mormente na situação em que o rotor operou em rotações $(\mathrm{N})$ mais elevadas. A perda de capacidade de bombeamento se deve ao fato de que tais células são do tipo sub-aeradas, onde o ar é introduzido no sistema através de vácuo gerado pela rotação do rotor.

Palavras-chave: Células de flotação, hidrodinâmica, bombeamento.

\begin{abstract}
The ability of impellers to produce bulk fluid flow may be expressed by the impeller flow rate $\left(Q_{b}\right)$ or the pumping number $\left(N_{Q}\right)$. Both parameters are very useful to characterize the hydrodynamics of mechanical flotation cells. In this work, an apparatus composed of a micromolen attached to an optic sensor was used to determine the impeller's water flow velocity $\left(v_{b}\right), Q_{b}$ and $N_{Q}$ of a Denver laboratory flotation cell from the Laboratory of Mineral Processing, University of São Paulo. Under usual working conditions (1,100-1,300 rpm), in the presence and absence of air, the equipment operates at $v_{b}=20-30 \mathrm{~cm} / \mathrm{s}, Q_{b}=298-454 \mathrm{~cm}^{3} / \mathrm{s}$ e $N_{Q} \sim 0,05$. The value of $N_{Q}$ related to a laboratory cell was similar to an industrial one $\left(N_{Q} \sim 0.05\right)$. Since Denver cells are sub-aerated, the presence of air in the system decreased the magnitude of $v_{b}$ and $Q_{b}$ when the impeller operated under higher rotational speed.
\end{abstract}

Keywords: Flotation cell, hydrodynamics, pumping. 


\section{Introdução}

Em células mecânicas de flotação, para que ocorra colisão entre bolhas e partículas, é necessário que essas estejam adequadamente suspensas no meio aquoso. Tal suspensão advém da ação mecânica do rotor (também chamado de impelidor) sobre o meio, promovendo, continuamente, um fluxo ascendente de polpa dentro da célula, como está ilustrado na Figura 1. Tal fluxo se contrapõe à natural tendência das partículas à sedimentação, decorrente da influência do campo gravitacional da Terra. As linhas de fluxo decorrentes da ação do impelidor encontram-se em uma região da célula denominada zona de coleta, região onde ocorrem as interações partículabolha, ou seja, colisão e adesão.

Assim como bombas centrífugas, células mecânicas de flotação são membros da família das turbo-máquinas. Em tais equipamentos, a polpa entra no sistema paralelamente ao eixo do rotor e é arremessada para a periferia em trajetória normal ao eixo (Figura 2). O volume de polpa por unidade de tempo deslocado pelo sistema é denominado de vazão de bombeamento $\left(\mathrm{Q}_{\mathrm{b}}\right)$.

Devido à ação dos rotores, fluidos exibem dois tipos de movimento no interior de um tanque agitado: bombeamento e vibração. O bombeamento, também chamado de bulk fluid flow (BFF), está associado à macroturbulência no interior do tanque; enquanto que a vibração, ou turbulent fluid motion (TFM), é decorrente de microturbulência. Nas células mecânicas de flotação, BFF é responsável pela suspensão das partículas no interior do tanque, assim como pela qualidade da mistura efetuada pelo impelidor. TFM é responsável pela dispersão das bolhas de ar no interior do tanque e, também, pela colisão entre partículas e bolhas.

A capacidade exibida por rotores de gerar BFF pode ser caracterizada por sua vazão de bombeamento $\left(\mathrm{Q}_{\mathrm{b}}\right)$ ou por parâmetro adimensional denominado Número de Bombeamento $\left(\mathrm{N}_{\mathrm{Q}}\right)$. De acordo com a equação $1, \mathrm{~N}_{\mathrm{Q}}$ é função não so-

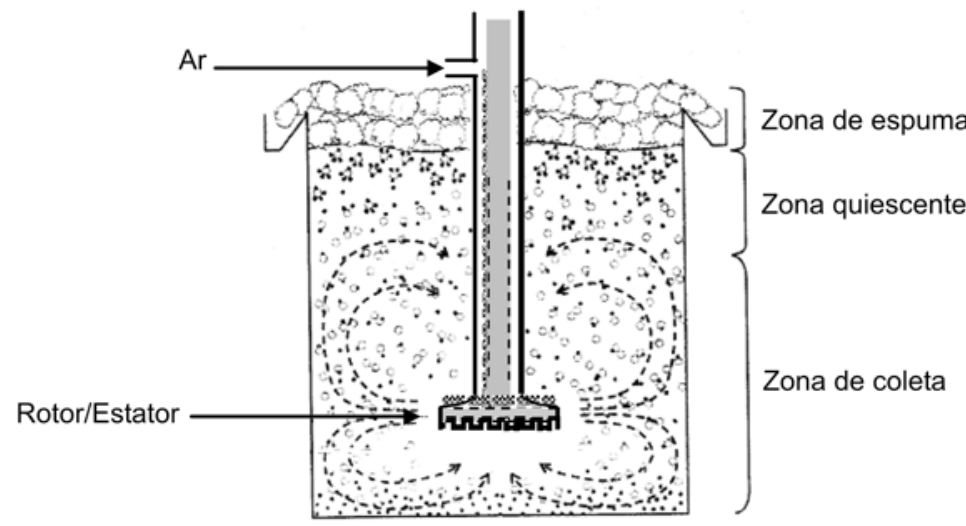

Figura 1 - Padrões de fluxo numa célula de flotação.

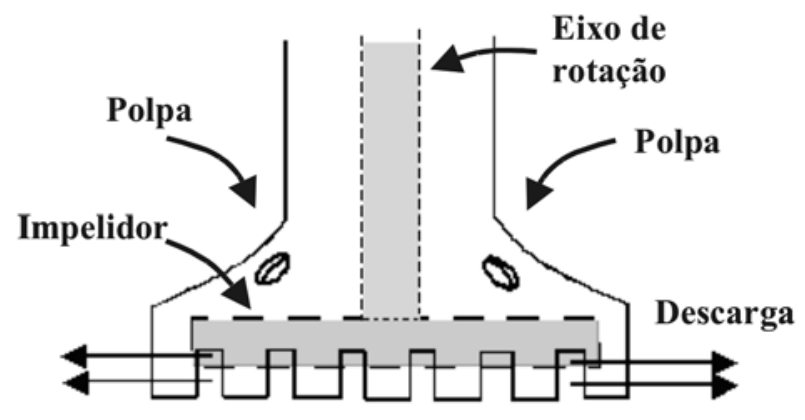

Figura 2 - Descarga de fluido na região rotor/estator.

mente de $\mathrm{Q}_{\mathrm{b}}$, mas da rotação $(\mathrm{N})$ e diâmetro (D) do rotor.

$N_{Q}=\frac{Q_{b}}{N D^{3}}$ (equação 1)

Para impelidores de mesma geometria e fluido de operação, $Q_{b}$ varia em função de seu diâmetro (D) e rotação $(\mathrm{N})$. Na verdade, $Q_{b}$ varia em função do número de Reynolds, sendo constante no regime laminar, crescente no regime de transição e constante em escoamentos turbulentos (Gomide, 1997).

Quanto mais alta for a magnitude do $\mathrm{N}_{\mathrm{Q}}$ apresentada por um impelidor, maior sua capacidade de executar o bombeamento da polpa dentro da célula. A literatura informa que rotores de tanques agitados industriais operam na faixa de $0,5<\mathrm{N}_{\mathrm{Q}}<0,87$ (McCabe, 1993); no entan- to, alguns autores reportaram valores de $\mathrm{N}_{\mathrm{Q}}>1$ (Bertrand et al., 1980; Holmes et al., 1964). Tais variações são função da forma e desenho dos impelidores. Células industriais modelo Eimco apresentam $\mathrm{N}_{\mathrm{Q}} \sim 0,64$ (EIMCO). Interessante ressaltar que a maior parte das informações existentes em literatura sobre $\mathrm{N}_{\mathrm{Q}}$ é relativa a tanques agitados e não propriamente às células de flotação. Nenhuma informação é encontrada em literatura corrente sobre $\mathrm{N}_{\mathrm{Q}}$ de células de bancada.

Entre as técnicas que podem ser utilizadas, para avaliar a capacidade de bombeamento de impelidores, destacase o micromolinete (MM), que apresenta maior praticidade e menor custo que outras técnicas citadas em literatura, como Laser Doppler Velocimmetry (Wu e Patterson, 1988). Holmes e colabora- 
Odair Alves de Lima et al.

dores (Holmes et al., 1964) mediram a descarga volumétrica de turbinas de Rushton, em tanques agitados, fazendo uso de tal técnica. O MM também tem sido utilizado pela engenharia hidráulica em diferentes aplicações (Wenniger \& Janauer, 1991; Ortiz, 1983).

O MM é composto por uma haste de aço inoxidável, em cuja extremidade há uma gaiola que sustenta os mancais, onde está apoiado o eixo de uma hélice. Conforme ilustra a Figura 3, o sistema hélice-gaiola-mancais funciona adaptado a um condicionador de sinais, que produz uma onda quadrada, onde cada borda positiva da onda corresponde à passagem de uma das pás da hélice pela haste vertical superior, onde está localizado um sensor ótico. O sinal emitido pelo condicionador é totalizado e armazenado em um contador, que os apresenta, continuamente, em um painel. Através de um circuito temporizador, é possível controlar o intervalo de tempo para que a contagem dos pulsos seja totalizada no contador.

\section{Materiais e métodos \\ 2.1 Determinação da capacidade de bombeamento do impelidor}

Para determinar a capacidade de bombeamento do impelidor, foi utilizado um micromolinete (MM) fornecido pelo Centro Tecnológico de Hidráulica da Escola Politécnica da Universidade de São Paulo. Tal aparato é composto por haste de aço inoxidável de $50 \mathrm{~cm}$ de comprimento, gaiola de diâmetro de $1,5 \mathrm{~cm}$, hélice composta de 5 pás com diâmetro de $1,1 \mathrm{~cm}$. O MM foi conectado a um contador/temporizador dotado de condicionador de sinais (Figura 3). Em todas as medições, a hélice foi posicionada na descarga do estator da célula, sempre na mesma posição, alinhada com o plano do disco que compõe o impelidor.

Os experimentos utilizaram água destilada como fluido de trabalho, na presença e ausência de aeração, numa célula de flotação Denver de laboratório, dotada de cuba de acrílico de
$5000 \mathrm{~cm}^{3}$. A freqüência de rotação da hélice do micromolinete $(\mathrm{X})$ foi medida sob diferentes rotações do impelidor: $900 \leq \mathrm{N} \leq 1400 \mathrm{rpm}$, após um tempo de contagem (T) de $60 \mathrm{~s}$, de acordo com a equação 2. Para cada particular rotação do impelidor $(\mathrm{N})$, eram efetuadas 10 leituras, extraindo-se média aritmética e desvio-padrão.

$$
X=\frac{\mathrm{n}}{\mathrm{T}}\left[\mathrm{s}^{-1}\right]
$$

(Equação 2)

Onde: n é o número de vezes que as pás da hélice do micromolinete passaram pelo ponto de detecção do sensor ótico e T é o intervalo de tempo em que as contagens foram feitas [s].

A velocidade de escoamento da água, na descarga do sistema rotor/estator $\left(\mathrm{v}_{\mathrm{b}}\right)$, foi determinada com base nos valores medidos da frequiência de rotação do micromolinete $(\mathrm{X})$, utilizando-se a equação 3. Tal equação, denominada curva de calibração do micromolinete, foi fornecida pelo Centro Tecnológico de Hidráulica da Universidade de São Paulo, provedor do MM.

$\mathrm{V}_{\mathrm{b}}=0,59 \cdot \mathrm{X}+3,16[\mathrm{~cm} / \mathrm{s}] \quad$ (Equação 3)

A velocidade periférica do impelidor $\left(v_{p}\right)$ foi calculada em função de sua rotação $(\mathrm{N})$ e diâmetro $(\mathrm{D}=7 \mathrm{~cm})$, utilizando-se a equação 4 .

$\mathrm{v}_{\mathrm{p}}=\pi \mathrm{ND} \quad($ Equação 4$) \quad \mathrm{u}(\mathrm{t})=\mathrm{U}+\mathrm{u}^{\prime}(\mathrm{t})$

\subsection{Tempo de contagem do número de rotações do micromolinete}

O escoamento de polpa em células mecânicas de flotação é altamente turbulento, uma vez que rotores exibem número de Reynolds da ordem de $10^{5}$ para células de laboratório e $10^{6}$ para células industriais (Harris, 1976). Em escoamentos turbulentos, conforme expressa a Equação 6, a velocidade instantânea $u(t)$ é o resultado da combinação de flutuações de velocidade u'(t) em torno de um valor médio (U), que caracteriza o escoamento em estado estacionário.

(Equação 6)

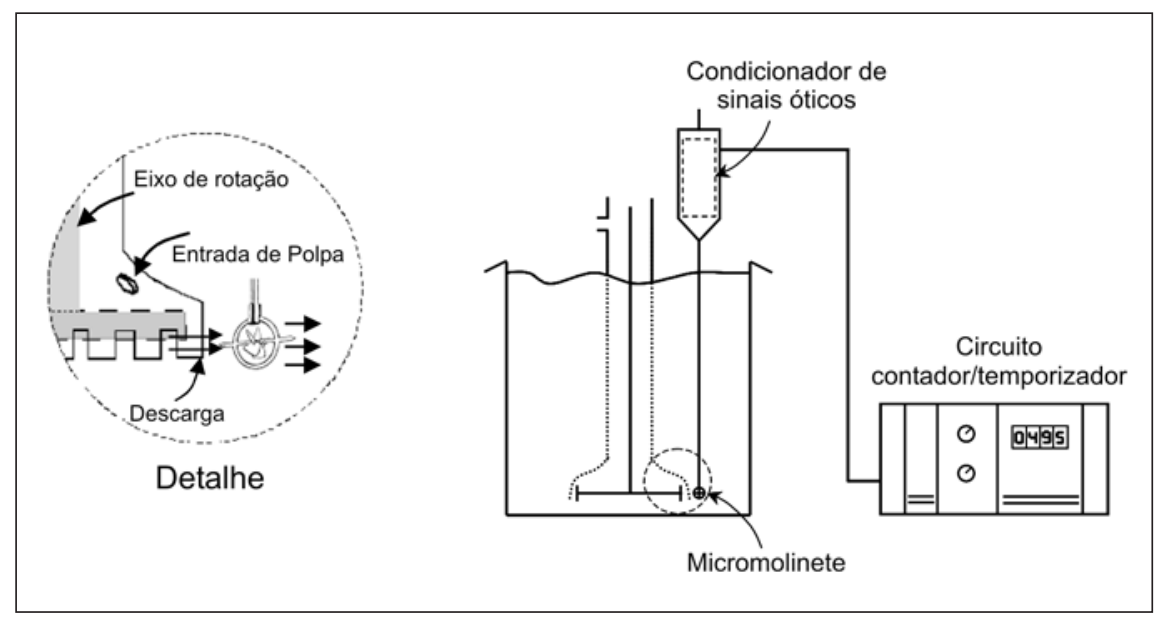

Figura 3 - Montagem experimental utilizada. Detalhe para o micromolinete na região rotor/estator. 
De acordo com a equação 7 , a velocidade média temporal (U) do escoamento é função do tempo de contagem $\mathrm{T}$, também chamado de tempo de medição. Deste modo, tal parâmetro é de suma importância na caracterização de sistemas turbulentos.

$U=\frac{1}{T} \cdot \int_{0}^{T} u(t) \cdot d t \quad$ (Equação 7)

Da equação 6, pode-se inferir que as determinações experimentais da velocidade média (U) de escoamento devem adotar valores de T suficientemente longos, a fim de minimizar variações em torno do valor médio. Conforme ilustra a Figura 4, uma vez que a magnitude de X estabilizou-se, praticamente, a partir de $\mathrm{T}=30 \mathrm{~s}$, adotou-se tempo de contagem duas vezes maior $(\mathrm{T}=60 \mathrm{~s})$ durante todas as medidas.

\section{Resultados e discussão}

Variando-se a rotação $(\mathrm{N})$ do impelidor e medindo-se a freqüência de rotação do molinete $(\mathrm{X})$, calculou-se a velocidade média de escoamento $\left(\mathrm{v}_{\mathrm{b}}\right)$ da água na descarga do estator através da equação 2 . Os resultados são apresentados na Figura 5, onde se pode verificar que $20-30 \mathrm{~cm} / \mathrm{s}$ constituem os valores de $\mathrm{v}_{\mathrm{b}}$ para células de flotação Denver de laboratório operando com $900 \mathrm{rpm}<\mathrm{N}<1400 \mathrm{rpm}$. Tais valores são bastante inferiores aos da velocidade periférica $\left(\mathrm{v}_{\mathrm{p}}\right)$ do rotor calculados para a mesma faixa de rotação:330-513cm/s. Tamanha discrepância pode ser devida ao encapsulamento do rotor pelo estator, diminuindo a capacidade do primeiro em gerar bulk fluid flow (BFF). Westhuizen (2004) exemplificou a influência de tal fenômeno sobre a suspensão de sólidos em células mecânicas.

Células Denver são células do tipo subaeradas, isto é, aquelas onde o ar é introduzido no sistema através da queda de pressão (vácuo) causada pelo movimento do rotor. Desse modo, quanto mais alta for a rotação do impelidor

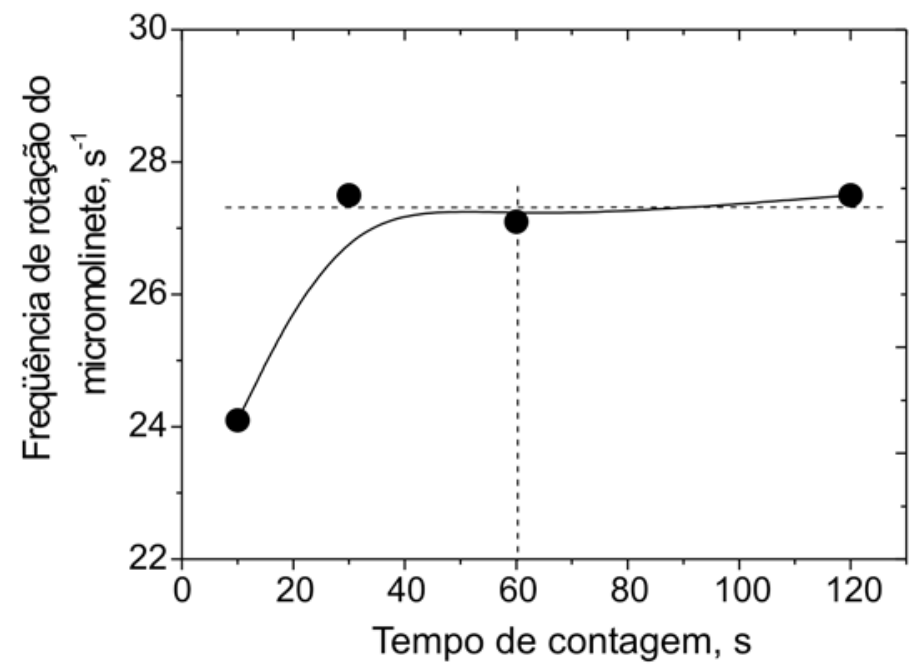

Figura 4 - Freqüência de rotação do micro molinete $(X)$ versus tempo de contagem $(T)$.

(N), maior será o fluxo de ar que escoará, em conjunto com a água, através da descarga na periferia do estator.

Através das Figuras 5 e 6, quando se trabalhou com a válvula de ar aberta, verificou-se uma diminuição, tanto de $v_{b}$, quanto de $\mathrm{Q}_{\mathrm{b}}$, em relação aos valores obtidos, quando a célula operou com a entrada de ar fechada, principalmente para rotações elevadas ( $>1200 \mathrm{rpm}$ ). Uma vez que, pela equação $5, v_{b}$ é a razão entre $\mathrm{Q}_{\mathrm{b}}$ e a área pela qual escoa o fluido, a diminuição da magnitude de $\mathrm{v}_{\mathrm{b}}$ e $\mathrm{Q}_{\mathrm{b}}$, na presença de ar, poderia ser explicada pela diminuição da capacidade do sistema mecânico rotor/estator de gerar bombeamento (bulk fluid flow). Desse modo, girando a $1.200 \mathrm{rpm}\left(\mathrm{N}=20 \mathrm{~s}^{-1}\right)$, o impelidor foi capaz de bombear $393 \mathrm{~cm}^{3} / \mathrm{s}$ na ausência de ar (válvula de ar fechada) versus $376 \mathrm{~cm}^{3} / \mathrm{s}$ na presença de ar (válvula aberta). Semelhante comportamento também é exibido por bom- bas centrífugas, quando são obrigadas a recalcar polpa ou água contendo bolhas de ar dispersas no meio.

Aplicando-se a equação 1 aos dados exibidos na Figura 6, determinou-se o número de bombeamento $\left(\mathrm{N}_{\mathrm{Q}}\right)$ do impelidor da célula de flotação que constitui o objeto desse trabalho. Os resultados são apresentados na Tabela 1, que, também, reporta o valor de $\mathrm{N}_{\mathrm{O}}$ determinado para impelidor de célula Denver modelo DR100, que opera em usina de flotação de silvita, pertencente à Cia Vale do Rio Doce (Amira, 2005). Em todos os casos, um valor de $\mathrm{N}_{\mathrm{Q}} \sim 0,05$ indica que a vazão real de bombeamento exibida pelo rotor $\left(\mathrm{Q}_{\mathrm{b}}\right)$ corresponde a somente $5 \%$ do valor de referência $\mathrm{ND}^{3}$, independentemente do rotor Denver operar em célula de laboratório ou industrial. Uma vez que os valores de $\mathrm{N}_{\mathrm{Q}}$, para escala de laboratório, são muito próximos ao valor obtido para escala industrial, tal número adi-

Tabela 1 - Número de Bombeamento $\left(\mathrm{N}_{\mathrm{Q}}\right)$ do impelidor de células Denver.

\begin{tabular}{c|c|c}
\hline \multicolumn{2}{c|}{ Modelo de Laboratório } & Modelo Denver DR100(*) \\
\hline Com aeração & Sem aeração & (Amira, 2005) \\
\hline 0,05 & 0,06 & 0,05 \\
\hline${ }^{(*)}$ Hold-up do ar $=9 \%$ quando da realização do experimento (Amira, 2005).
\end{tabular}


Odair Alves de Lima et al.

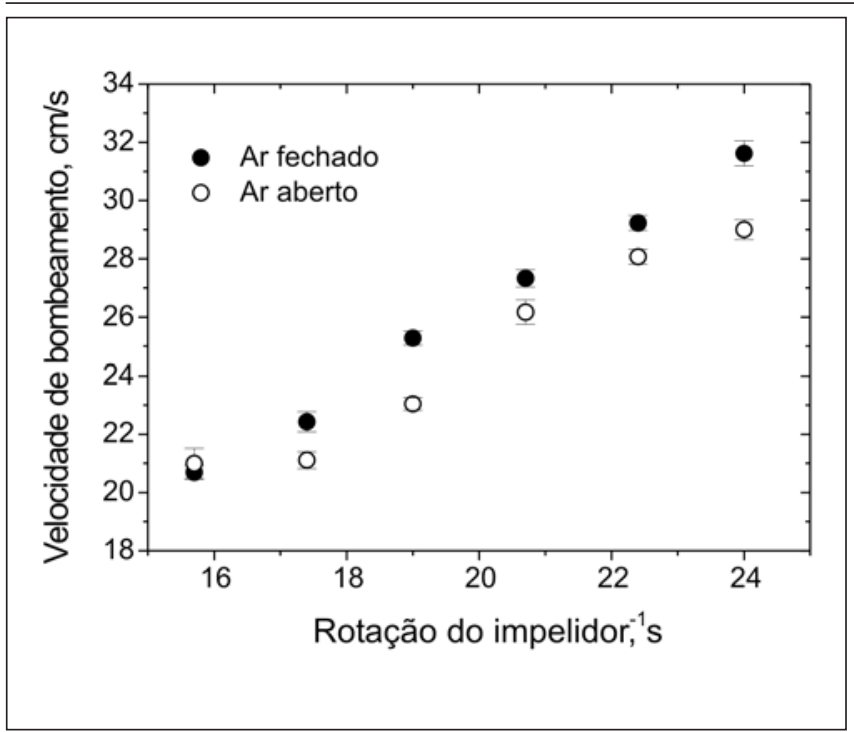

Figura 5 - Velocidade de descarga na saída do estator $\left(\mathrm{v}_{\mathrm{b}}\right)$ versus rotação do impelidor $(\mathrm{N})$.

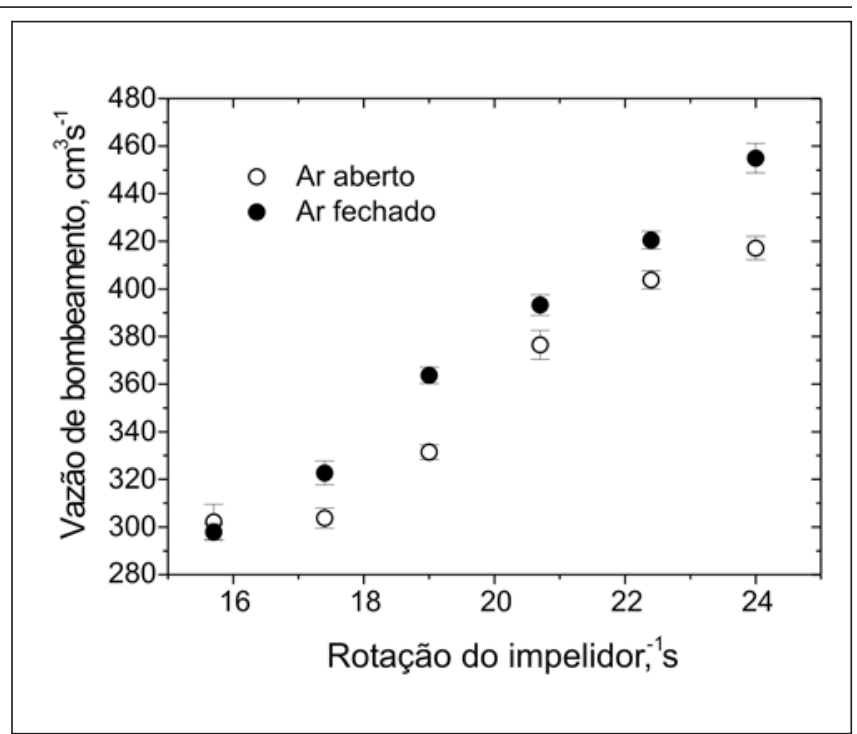

Figura 6 - Vazão de bombeamento $\left(Q_{b}\right)$ versus rotação do impelidor. mensional se mostra apropriado para ser utilizado no escalonamento de células mecânicas de flotação.

\section{Conclusões}

A capacidade de bombeamento de rotores pode ser expressa em função de sua vazão de bombeamento $\left(\mathrm{Q}_{\mathrm{b}}\right)$ ou de seu número de bombeamento $\left(\mathrm{N}_{\mathrm{Q}}\right)$. Ambos parâmetros são muito importantes na caracterização hidrodinâmica de células mecânicas de flotação. Nesse trabalho, utilizou-se o micromolinete (MM) para determinar $\mathrm{Q}_{\mathrm{b}}, \mathrm{N}_{\mathrm{Q}} \mathrm{e}$, também, para determinar a velocidade de escoamento da água $\left(\mathrm{v}_{\mathrm{b}}\right)$, na descarga do rotor de uma célula Denver, modelo de laboratório, usualmente utilizada em ensaios de bancada no Laboratório de Tratamento de Minerais da Escola Politécnica da USP. Os resultados indicaram que tal célula, dentro das condições operacionais usualmente utilizadas em escala de bancada (900rpm< $<\mathrm{N}<1400 \mathrm{rpm})$, opera dentro das seguintes condições: $\mathrm{v}_{\mathrm{b}}=20-30 \mathrm{~cm} / \mathrm{s}$, $\mathrm{Q}_{\mathrm{b}}=298-454 \mathrm{~cm}^{3} / \mathrm{s} \mathrm{e}_{\mathrm{Q}} \sim 0,05$. Tal valor de $\mathrm{N}_{\mathrm{Q}}$ apresentou magnitude similar à obtida para uma célula Denver que opera em escala industrial na flotação de silvita $\left(\mathrm{N}_{\mathrm{Q}} \sim 0,05\right)$. Tal constatação indica que o número adimensional $\mathrm{N}_{\mathrm{Q}}$ pode ser útil no escalonamento de equipamentos. A presença de ar no sistema se mostrou capaz de diminuir a magnitude, tanto de $\mathrm{v}_{\mathrm{b}}$, quanto de $\mathrm{Q}_{\mathrm{b}}$, mormente na situação em que o rotor operou em rotações $(\mathrm{N})$ mais elevadas ( $>1200 \mathrm{rpm})$. A perda de capacidade de bombeamento, devida à presença de ar, se deve, provavelmente, ao fato de que células Denver são do tipo subaeradas, onde o ar é introduzido no sistema através de vácuo gerado pela rotação do rotor. Tal perda de capacidade é característica, não somente de células de flotação, mas, também, de outras turbomáquinas, como as bombas centrífugas.

\section{Agradecimentos}

Os autores gostariam de agradecer ao Centro Tecnológico de Hidráulica (CTH), pelo empréstimo de equipamento e suporte técnico, assim como à CAPES e ao CNPq, pela concessão de bolsas de pesquisa.

\section{Referências bibliográficas}

AMIRA P260D PROJECT, 2005.

BERTARND, J., COUDERC J. P., ANGELINO, H. Power consumption, pumping capacity and turbulence intensity in baffled stirred tanks: comparation between several turbines. Chemical Eng. Science, v. 35, p. $2157-$ 2163,1980.
GOMIDE, R. Operações unitárias. Volume II-Operações com Fluidos $2^{\text {a }}$ Parte. São Paulo: Gráfica Palas Athenas. 1997.

HARRIS, C. C. Flotation machines. Flotation-A. M. Gaudin Memorial, v. 2, p. 753-815, 1976.

HOLMES, D. B., VONCKEN, R. M., DEKKER, J. A. Fluid flow in turbinestirred, baffled tanks - Part I circulation time. Chemical Eng. Science, v. 19, p. 201-208, 1963.

McCABE, W. L., SMITH, J. C., HARRIOT, P. Unit operations of chemical engineering. $5^{\text {th }}$ Ed. McGraw Hill, 1993.

ORTIZ, J. P. Macroturbulência de escoamento a jusante de estruturas de dissipação por ressalto. Estudo teóricoexperimental. Boletim Técnico DAEE, v. 5, n. 3, p. 237-472, São Paulo, 1982.

EIMCO PROCESS EQUIPMENTE COMPANY. WEMCO $\mathbf{1 + 1}$ Mechanical Machines. Salt Lake City, 1992. (WF5-092/BAK 3157)

WENIGER, C. M., JANAUER, G. A. The measurement of current velocities in microphyte beds. Aquatic Botany, n. 39. p. 221-230, 1991.

WESTHUIZEN, A. P. P. The evaluation of solids suspension in a pilot scale mechanical flotation cell. Universidade de Cape Town, 2004. (Dissertação de Mestrado).

WU, H., PATTERSON, G. K. Laser-doppler measurements of turbulent-flow parameters in a stirred mixer. Chemical Eng. Science, v. 44, p. 2207-2221, 1988.

Artigo recebido em 27/06/2006 e aprovado em 10/11/2006. 